\title{
Growing use of integrated e-health systems
}

Cite as: CMAJ 2017 August 21;189:E1075-6. doi: 10.1503/cmaj.1095455

Posted on cmajnews.com on Aug. 1, 2017.

overnment officials have long claimed that integrated provincial electronic health information systems are gathering momentum. And clinicians and researchers have long disputed that claim. In recent months, however, observers in Quebec, Ontario and elsewhere have begun to concede the official claims may be right.

Two recent studies point to uneven progress. Although a May 2017 Commonwealth Fund study noted that $73 \%$ of Canadian primary care physician use electronic records, Canada's use was still the second lowest among the study's 18 countries.

However, users of electronic health records increased five-fold to 160000 between 2012 and 2017, notes Simon Hagens, director of benefits realization and quality improvement at Canada Health Infoway, Ottawa's e-health agency.

And although a May 2017 report from Alberta's Auditor General notes that only $19 \%$ of Canadian doctors can exchange patient summaries electronically with other doctors, compared to $82 \%$ in Norway, Hagens says users within integrated records systems increased from one percent in 2014 to $19 \%$ in 2017.

"It's important progress," he says.

Some Ontario officials agree. For example, records for two-thirds of all drugs dispensed in Ontario went live last month on web-based viewing systems used by clinicians across the province. Doug Watt, vice president for product management at eHealth Ontario, the provincial government agency charged with integrating records systems, says "tremendous progress is being made."

Watt says eHealth Ontario completed "the foundational elements of the electronic health care record" in March and that more than 93000 authorized healthcare providers across the province can access patient records no matter where they were created through the province's two viewing systems: ClinicalConnect and ConnectOntario. Usage has expanded $21 \%$ over last year, Watt says.

Clinicians say the progress is heartening. "The connection of systems across Ontario is well underway," says Dr. Mohamed Alarakhia, chief clinical infor-

Health Network (UHN) identified 12 different health information teams, resulting in a "level of fragmentation" that "limits effectiveness." The audit, which was released to the CMAJ under the provincial Freedom of Information Act, said UHN's \$100-million health information budget was the second highest among 26 US comparators, and recommended that spending be cut by $25 \%$.

At McMaster University in Hamilton,

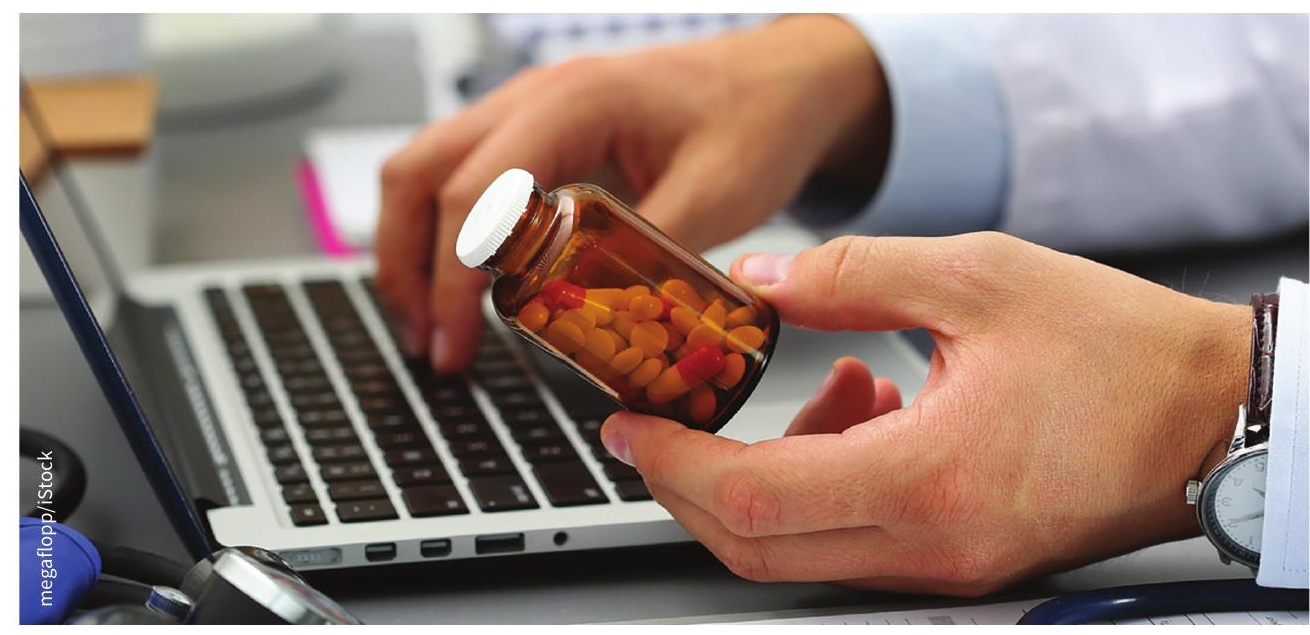

Encouraging signs emerging for e-health integration in Canada.

mation officer for the Waterloo Wellington Local Health Integration Network in southwest Ontario. Within that network, 67 acute care hospitals housing 42000 system users can now share diagnostic images, and laboratory and drug data for about 3.5 million people, or $30 \%$ of Ontario's population.

But while praising the progress Ontario is making, Alarakhia warns that incompatible systems are still being purchased with public funds due to overly permissive procurement policies.

A November 2015 audit of information technology at Toronto's University clinician-scientist Dr. Anne Holbrooke has mixed feelings about ClinicalConnect, which she says is "tedious" to use. "The concept is excellent, the delivery not so good yet. I do not know the potential to improve it," says Holbrooke. "If Clinical Connect was a more robust, faster system and covered all of Southern Ontario, I think we would be using it exclusively."

In Quebec, where an integrated Health Information Exchange system went live two years ago, usage is growing quickly, according to a study led by Aude Motulsky at the Université de Montréal, which she 
presented at the recent eHealth 2017 conference.

Analysis of usage data in Quebec between January 1, 2016 and July 31, 2016 presented by Motulsky at the recent Canadian Association for Health Services and Policy Research conference found that $80 \%$ of potentially authorized pharmacists and $66 \%$ of family physicians, but only $20 \%$ of specialists and $10 \%$ of nurses, accessed the Health Information Exchange system.
"Most pharmacists and the majority of [family physicians] in the province have adopted the tool," Motulsky reported at the conference. "Medication data was the domain that was used the most, indicating that it has broad value across clinical settings."

E-prescribing is also a priority for Infoway. In May 2017, it selected TELUS Health to come up with the technology for a national system. Dave Wattling,
TELUS Health vice-president and chief corporate development officer, describes the e-prescribing system as a platform for an array of functions beyond medication management, including e-referrals, patient bookings, inter-clinician messaging.

"Our vision is to create a platform that can deliver all of this," he says.

Paul Webster, Toronto, Ont. 